\title{
TU/e EmonOWEN

\section{Active and reactive power control schemes for distributed generation systems under voltage dips}

\section{Citation for published version (APA):}

Wang, F., Duarte, J. L., \& Hendrix, M. A. M. (2009). Active and reactive power control schemes for distributed generation systems under voltage dips. In Proceedings IEEE Energy Conversion Congress and Exposition (ECCE 2009), 20-24 September 2009, San Jose, California (pp. 3564-3571). Institute of Electrical and Electronics Engineers. https://doi.org/10.1109/ECCE.2009.5316564

DOI:

10.1109/ECCE.2009.5316564

Document status and date:

Published: 01/01/2009

\section{Document Version:}

Publisher's PDF, also known as Version of Record (includes final page, issue and volume numbers)

\section{Please check the document version of this publication:}

- A submitted manuscript is the version of the article upon submission and before peer-review. There can be important differences between the submitted version and the official published version of record. People interested in the research are advised to contact the author for the final version of the publication, or visit the $\mathrm{DOI}$ to the publisher's website.

- The final author version and the galley proof are versions of the publication after peer review.

- The final published version features the final layout of the paper including the volume, issue and page numbers.

Link to publication

\section{General rights}

Copyright and moral rights for the publications made accessible in the public portal are retained by the authors and/or other copyright owners and it is a condition of accessing publications that users recognise and abide by the legal requirements associated with these rights.

- Users may download and print one copy of any publication from the public portal for the purpose of private study or research.

- You may not further distribute the material or use it for any profit-making activity or commercial gain

- You may freely distribute the URL identifying the publication in the public portal.

If the publication is distributed under the terms of Article 25fa of the Dutch Copyright Act, indicated by the "Taverne" license above, please follow below link for the End User Agreement:

www.tue.nl/taverne

Take down policy

If you believe that this document breaches copyright please contact us at:

openaccess@tue.nl

providing details and we will investigate your claim. 


\title{
Active and Reactive Power Control Schemes for Distributed Generation Systems Under Voltage Dips
}

\author{
Fei Wang, Jorge L. Duarte and Marcel A. M. Hendrix \\ Department of Electrical Engineering \\ Eindhoven University of Technology \\ 5600 MB Eindhoven, The Netherlands \\ Email: f.wang@tue.nl
}

\begin{abstract}
During voltage dips continuous power delivery from distributed generation systems to the grid is desirable for the purpose of grid support. In order to facilitate the control of distributed generation systems adapted to the expected change of grid requirements, generalized power control schemes based on symmetric-sequence components are proposed in this paper for inverter-based distributed generation, aiming at manipulating the delivered instantaneous power under voltage dips. It is shown that active power and reactive power can be independently controlled with two individually adaptable parameters. By changing these parameters, the relative amplitudes of oscillating power can be smoothly regulated, as well as the peak values of three-phase grid currents. As a result, the power control of grid-side inverters becomes quite flexible. Furthermore, two strategies for simultaneous active and reactive power control are proposed that preserves adaptive controllability. Finally, the proposed schemes are verified experimentally.
\end{abstract}

\section{INTRODUCTION}

Voltage dips, usually caused by remote grid faults in the power system, are short-duration decreases in rms voltage. Most voltage dips are due to unbalanced faults, while balanced voltage dips are relatively rare in practice [1] [2]. Conventionally, a distributed generation (DG) system would be required to disconnect from the grid when voltage dips and to reconnect to the grid when faults are cleared. However, this requirement is changing. With the increasing application of renewable energy sources, more and more DG systems actively deliver electricity into the grid. In particular, wind power generation becomes an important electricity source in many countries. Consequently, in order to maintain active power delivery and reactive power support to the grid, grid codes now require wind energy systems to ride through voltage dips without interruption [3] [4]. For the future scenario of a grid with significant DG penetration, it is necessary to investigate the ride-through control of wind turbine systems and other DG systems as well. Disregarding various upstream distributed sources and their controls, the control of DG inverters will be focused on in this paper.

Concerning the control of DG inverters under voltage dips, especially unbalanced situations, two aspects should be noticed. Firstly, fast system dynamics and good reference tracking are necessary. Controllers must be able to deal with all the symmetric-sequence components and to have fast feedback signals for closed-loop control. Secondly, in case of unbalanced voltage dips, the generation of reference currents is important. Because this paper focuses on the second aspect, the control structure of such inverters will be presented in the part of experimental verification.

Under unbalanced voltage dips, current reference generation is constrained by trade-offs. Considering the powerelectronics converter constraints, a constant dc-link voltage is desirable [5] and [6]. However, a constant dc bus is achieved at the cost of unbalanced grid currents, and this results in a decrease of maximum deliverable power. In [7], a power reducing scheme is used to confine the current during a grid fault. On the other hand, the effects of the grid currents on the power system side should also be taken into account when assigning reference currents for DG inverters. As presented in [8][9], several specific strategies are possible in order to get different power quality levels at the grid connection point in terms of instantaneous power oscillation and current distortion. One of the methods in [8], which is based on instantaneous power theory [10], obtains zero instantaneous power oscillation but generates distorted grid currents due to asymmetry of grid voltages. Other methods in [8] lead to sinusoidal output currents. These strategies show flexible control possibilities of DG systems under grid faults. However, they only cope with specific cases. Therefore, starting from the ideas in [8], a generalized strategy on reference current generation is carried out in the following.

This paper proposes generalized and independent active and reactive power control strategies based on symmetricsequence components and shows explicitly the contributions of symmetrical sequences to instantaneous power under unbalanced voltage dips. The proposed strategy enables DG inverters to be optimally designed. Furthermore, two strategies for simultaneous active and reactive power control are proposed that preserves the adaptive controllability.

\section{Instantaneous Power Calculation}

To investigate power control strategy, the instantaneous power theory [10] [11] is revisited in this section. Then instantaneous power calculation based on symmetric sequences 
is developed, and the notation for the reference current design in the next sections is defined.

\section{A. Instantaneous Power Theory}

For a three-phase DG system, instantaneous active power and reactive power at the grid connection point are given by, respectively,

$$
\begin{aligned}
& p=\mathbf{v} \cdot \mathbf{i}=v_{a} i_{a}+v_{b} i_{b}+v_{c} i_{c} \\
& q=\mathbf{v}_{\perp} \cdot \mathbf{i}=\frac{1}{\sqrt{3}}\left[\left(v_{a}-v_{b}\right) i_{c}+\left(v_{b}-v_{c}\right) i_{a}+\left(v_{c}-v_{a}\right) i_{b}\right] \\
& \text { with } \quad \mathbf{v}_{\perp}=\frac{1}{\sqrt{3}}\left[\begin{array}{ccc}
0 & 1 & -1 \\
-1 & 0 & 1 \\
1 & -1 & 0
\end{array}\right] \mathbf{v}
\end{aligned}
$$

where $\mathbf{v}=\left[\begin{array}{lll}v_{a} & v_{b} & v_{c}\end{array}\right]^{T}, \mathbf{i}=\left[\begin{array}{ccc}i_{a} & i_{b} & i_{c}\end{array}\right]^{T}$, bold symbols represent vectors, and the operator "." denotes the dot product of vectors. Note that the subscript " $\perp$ " is used to represent a vector derived from the matrix transformation in (2), although vectors $\mathbf{v}_{\perp}$ and $\mathbf{v}$ are orthogonal only when the three-phase components in vector $\mathbf{v}$ are balanced.

\section{B. Symmetric-sequence Based Instantaneous Power}

Symmetric-sequence transformation is a proven way to decompose unbalanced multi-phase quantities [12]. Consequently, instantaneous quantities for unbalanced a-b-c voltages are represented by

$$
\mathbf{v}=\mathbf{v}^{+}+\mathbf{v}^{-}+\mathbf{v}^{0}
$$

where $\mathbf{v}^{+,-, 0}=\left[\begin{array}{lll}v_{a}^{+,-, 0} & v_{b}^{+,-, 0} & v_{c}^{+,-, 0}\end{array}\right]^{T}$, and subscripts ".", "-", and "0" denote positive, negative, and zero sequences, respectively.

Similarly, current quantities can also be represented in terms of symmetric sequences, i.e.

$$
\mathbf{i}=\mathbf{i}^{+}+\mathbf{i}^{-}+\mathbf{i}^{0},
$$

where $\mathbf{i}^{+,-, 0}=\left[\begin{array}{lll}i_{a}^{+,-, 0} & i_{b}^{+,-, 0} & i_{c}^{+,-, 0}\end{array}\right]^{T}$. As a result, the calculation of instantaneous power in (1) and (2) can be rewritten as

$$
\begin{gathered}
p=\mathbf{v} \cdot \mathbf{i}=\left(\mathbf{v}^{+}+\mathbf{v}^{-}+\mathbf{v}^{0}\right) \cdot\left(\mathbf{i}^{+}+\mathbf{i}^{-}+\mathbf{i}^{0}\right), \\
q=\mathbf{v}_{\perp} \cdot \mathbf{i}=\left(\mathbf{v}_{\perp}^{+}+\mathbf{v}_{\perp}^{-}+\mathbf{v}_{\perp}^{0}\right) \cdot\left(\mathbf{i}^{+}+\mathbf{i}^{-}+\mathbf{i}^{0}\right) .
\end{gathered}
$$

With respect to the definitions of the symmetric-sequence vector in (3), corresponding orthogonal vectors in (6) can be derived by using the matrix transformation in (2). Note that $\mathbf{v}_{\perp}^{+}$lags $\mathbf{v}^{+}$by $90^{0}, \mathbf{v}_{\perp}^{-}$leads $\mathbf{v}^{-}$by $90^{\circ}$, and $\mathbf{v}_{\perp}^{0}$ is always equal to zero. Because the dot products between $\mathbf{i}^{0}$ and positive-sequence or negative-sequence voltage vectors are also always zero (due to symmetry of the components in $\mathbf{v}^{+}$and $\mathbf{v}^{-}$), equation (5) and (6) can be simplified by

$$
\begin{array}{r}
p=\mathbf{v} \cdot \mathbf{i}=\left(\mathbf{v}^{+}+\mathbf{v}^{-}\right) \cdot\left(\mathbf{i}^{+}+\mathbf{i}^{-}\right)+\mathbf{v}^{0} \cdot \mathbf{i}^{0}, \\
q=\mathbf{v}_{\perp} \cdot \mathbf{i}=\left(\mathbf{v}_{\perp}^{+}+\mathbf{v}_{\perp}^{-}\right) \cdot\left(\mathbf{i}^{+}+\mathbf{i}^{-}\right) .
\end{array}
$$
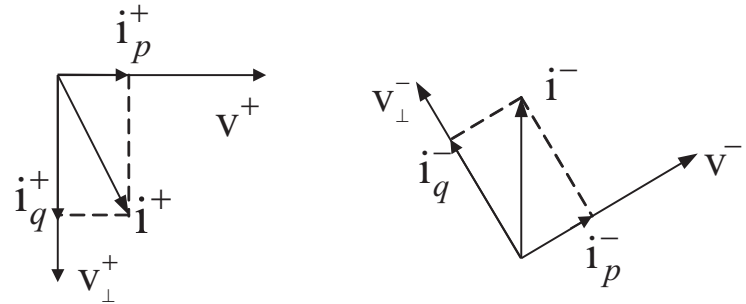

Fig. 1. Decomposition of currents for independent PQ control.

Because the calculation of instantaneous power and current references is carried out in terms of vectors, it can also be used in other reference frames, simply by substituting the vectors in the $a-b-c$ frames with vectors derived in other frames, for example, the stationary $\alpha-\beta-\gamma$ reference frame.

In next sections, current control based only on positivesequence and negative-sequence components is investigated. Because zero-sequence voltages of unbalanced voltage dips do not exist in three-wire systems, nor can they propagate to the secondary side of star-ungrounded or delta connected transformers in four-wire systems, most case-studies only consider positive and negative sequences. Even for unbalanced systems with zero-sequence voltage, four-leg inverter topologies can eliminate zero-sequence current with appropriate control. Simplifying assumptions we will use:

- Only positive-sequence and negative-sequence currents are present;

- Only fundamental voltages exist, in practice they can be extracted out;

- The amplitude of the positive-sequence voltage is higher than the negative sequence.

\section{Strategies for IndePendent P\&Q CONTROL}

In order to separately analyze the contribution of currents to independent active and reactive power control, sequence currents $\mathbf{i}^{+,-}$can be decoupled into two orthogonal quantities, i.e. $\mathbf{i}_{p}^{+,-}$and $\mathbf{i}_{q}^{+,-}$, as depicted in Fig. 1. The subscript " $p$ " represents active power related quantities, and " $q$ " reactive power related quantities.

\section{A. Reactive Power Control}

For reactive power control, only $\mathbf{i}_{q}^{+}$and $\mathbf{i}_{q}^{-}$are present, which are defined in phase with $\mathbf{v}_{\perp}^{+}$and $\mathbf{v}_{\perp}^{-}$, respectively, in order to generate reactive power only. Rewriting (7) and (8) in terms of $\mathbf{i}_{q}^{+}$and $\mathbf{i}_{q}^{-}$, we obtain

$$
\begin{aligned}
& p=\underbrace{\mathbf{v}^{+} \cdot \mathbf{i}_{q}^{-}+\mathbf{v}^{-} \cdot \mathbf{i}_{q}^{+}}_{\tilde{p}_{2 \omega}}, \\
& q=\underbrace{\mathbf{v}_{\perp}^{+} \cdot \mathbf{i}_{q}^{+}}_{Q^{+}}+\underbrace{\mathbf{v}_{\perp}^{-} \cdot \mathbf{i}_{q}^{-}}_{Q^{-}}+\underbrace{\mathbf{v}_{\perp}^{-} \cdot \mathbf{i}_{q}^{+}+\mathbf{v}_{\perp}^{+} \cdot \mathbf{i}_{q}^{-}}_{\tilde{q}_{2 \omega}},
\end{aligned}
$$

where $Q^{+}$and $Q^{-}$denote the constant reactive power introduced by positive and negative sequences, respectively, 
$\tilde{p}_{2 \omega}$ is oscillating active power, and $\tilde{q}_{2 \omega}$ oscillating reactive power. It can be found that the two terms of $\tilde{p}_{2 \omega}$ are in-phase quantities oscillating at twice the fundamental frequency. A similar property can be found for the two terms of $\tilde{q}_{2 \omega}$.

Because oscillating active power can reflect a variation on the DC-link voltage, and high DC voltage variation may cause over-voltage problems, output distortion, or even control instability, it is desirable to eliminate $\tilde{p}_{2 \omega}$. On the other hand, the oscillating reactive power $\tilde{q}_{2 \omega}$ also causes power losses and operating current rise, and therefore it is advantageous to mitigate $\tilde{q}_{2 \omega}$ as well. A trade-off between $\tilde{p}_{2 \omega}$ and $\tilde{q}_{2 \omega}$ is not straightforward and depends on practical requirements. In the following, strategies to achieve controllable oscillating active and reactive power are derived from two considerations.

\section{1) Controllable oscillating reactive power:}

For given reactive power $Q$, the first two terms of (10) are deigned to meet

$$
Q=\mathbf{v}_{\perp}^{+} \cdot \mathbf{i}_{q}^{+}+\mathbf{v}_{\perp}^{-} \cdot \mathbf{i}_{q}^{-} .
$$

Since the two terms of $\tilde{q}_{2 \omega}$ in (10) are in-phase quantities that add to each other, it is expected that these two terms can compensate each other. By setting intentionally

$$
\mathbf{v}_{\perp}^{+} \cdot \mathbf{i}_{q}^{-}=-k_{q} \mathbf{v}_{\perp}^{-} \cdot \mathbf{i}_{q}^{+}, \quad 0 \leq k_{q} \leq 1,
$$

after some manipulations the negative-sequence current $\mathbf{i}_{q}^{-}$is derived from (12) as

$$
\mathbf{i}_{q}^{-}=\frac{-k_{q} \mathbf{v}_{\perp}^{+} \cdot \mathbf{i}_{q}^{+}}{\left\|\mathbf{v}_{\perp}^{+}\right\|^{2}} \mathbf{v}_{\perp}^{-} .
$$

where $\left\|\mathbf{v}_{\perp}^{+}\right\|^{2}=\left\|\mathbf{v}^{+}\right\|^{2}=\mathbf{v}^{+} \cdot \mathbf{v}^{+}$, operator “ $\|\cdot\|$ " means the norm of a vector.

Substituting (13) into (11), and using $\left\|\mathbf{v}_{\perp}^{+,-}\right\|^{2}=$ $\left\|\mathbf{v}^{+,-}\right\|^{2}$, we obtain

$$
Q\left\|\mathbf{v}^{+}\right\|^{2}=\left(\left\|\mathbf{v}^{+}\right\|^{2}-k_{q}\left\|\mathbf{v}^{-}\right\|^{2}\right)\left(\mathbf{v}_{\perp}^{+} \cdot \mathbf{i}_{q}^{+}\right) .
$$

Then, based on (13) and (14), currents $\mathbf{i}_{q}^{+}$and $\mathbf{i}_{q}^{-}$can be calculated as

$$
\begin{aligned}
& \mathbf{i}_{q}^{+}=\frac{Q}{\left\|\mathbf{v}^{+}\right\|^{2}-k_{q}\left\|\mathbf{v}^{-}\right\|^{2}} \mathbf{v}_{\perp}^{+}, \\
& \mathbf{i}_{q}^{-}=\frac{-k_{q} Q}{\left\|\mathbf{v}^{+}\right\|^{2}-k_{q}\left\|\mathbf{v}^{-}\right\|^{2}} \mathbf{v}_{\perp}^{-} .
\end{aligned}
$$

Finally, the total current reference is the sum of $\mathbf{i}_{q}^{+}$and $\mathbf{i}_{q}^{-}$, that is

$$
\mathbf{i}_{q}^{*}=\frac{Q}{\left\|\mathbf{v}^{+}\right\|^{2}-k_{q}\left\|\mathbf{v}^{-}\right\|^{2}}\left(\mathbf{v}_{\perp}^{+}-k_{q} \mathbf{v}_{\perp}^{-}\right), \quad 0 \leq k_{q} \leq 1 .
$$

2) Controllable oscillating active power:

Instead of compensating the oscillating reactive power in (10), we can similarly control the oscillating active power in (9). For this purpose negative-sequence currents are imposed to meet

$$
\mathbf{v}^{+} \cdot \mathbf{i}_{q}^{-}=-k_{q} \mathbf{v}^{-} \cdot \mathbf{i}_{q}^{+}, \quad 0 \leq k_{q} \leq 1 .
$$

By considering equation $\mathbf{v}^{+} \cdot \mathbf{i}^{-}=\mathbf{v}^{+}{ }_{\perp} \cdot \mathbf{i}^{-}{ }_{\perp}$ (because $\mathbf{v}_{\perp}^{+}$ lags $\mathbf{v}^{+}$by $90^{\circ}$ and $\mathbf{i}_{\perp}^{-}$leads $\mathbf{i}^{-}$by $90^{\circ}$ ), the left side of (18) can be rewritten as

$$
\mathbf{v}^{+} \cdot \mathbf{i}_{q}^{-}=\mathbf{v}_{\perp}^{+} \cdot \mathbf{i}_{q \perp}^{-}=-k_{q} \mathbf{v}^{-} \cdot \mathbf{i}_{q}^{+},
$$

where $\mathbf{i}_{q \perp}^{-}$denotes the orthogonal vector of $\mathbf{i}_{q}^{-}$according to (2). Then, it follows that

$$
\mathbf{i}_{q \perp}^{-}=\frac{k_{q} \mathbf{v}_{\perp}^{+} \cdot \mathbf{i}_{q}^{+}}{\left\|\mathbf{v}^{+}\right\|^{2}} \mathbf{v}^{-} .
$$

Hence the negative-sequence current $\mathbf{i}_{q}^{-}$follows directly from (20) as

$$
\mathbf{i}_{q}^{-}=\frac{-k_{q} \mathbf{v}_{\perp}^{+} \cdot \mathbf{i}_{q}^{+}}{\left\|\mathbf{v}^{+}\right\|^{2}} \mathbf{v}_{\perp}^{-} .
$$

Solving (21) and (11), the positive-sequence current and negative-sequence current are derived as

$$
\begin{aligned}
& \mathbf{i}_{q}^{+}=\frac{Q}{\left\|\mathbf{v}^{+}\right\|^{2}+k_{q}\left\|\mathbf{v}^{-}\right\|^{2}} \mathbf{v}_{\perp}^{+}, \\
& \mathbf{i}_{q}^{-}=\frac{k_{q} Q}{\left\|\mathbf{v}^{+}\right\|^{2}+k_{q}\left\|\mathbf{v}^{-}\right\|^{2}} \mathbf{v}_{\perp}^{-} .
\end{aligned}
$$

Again, the total current reference is the sum of $\mathbf{i}_{q}^{+}$and $\mathbf{i}_{q}^{-}$, that is,

$$
\mathbf{i}_{q}^{*}=\frac{Q}{\left\|\mathbf{v}^{+}\right\|^{2}+k_{q}\left\|\mathbf{v}^{-}\right\|^{2}}\left(\mathbf{v}_{\perp}^{+}+k_{q} \mathbf{v}_{\perp}^{-}\right), \quad 0 \leq k_{q} \leq 1 .
$$

3) Merging strategies 1) and 2):

Simple analysis reveals that (17) and (24) can be put together as

$$
\mathbf{i}_{q}^{*}=\frac{Q}{\left\|\mathbf{v}^{+}\right\|^{2}+k_{q}\left\|\mathbf{v}^{-}\right\|^{2}}\left(\mathbf{v}_{\perp}^{+}+k_{q} \mathbf{v}_{\perp}^{-}\right), \quad-1 \leq k_{q} \leq 1 .
$$

Further, by substituting (25) into (9) and (10), it follows that

$$
\begin{gathered}
p=\frac{Q\left(1-k_{q}\right)\left(\mathbf{v}_{\perp}^{+} \cdot \mathbf{v}^{-}\right)}{\left\|\mathbf{v}^{+}\right\|^{2}+k_{q}\left\|\mathbf{v}^{-}\right\|^{2}}, \\
q=Q+\frac{Q\left(1+k_{q}\right)\left(\mathbf{v}_{\perp}^{+} \cdot \mathbf{v}_{\perp}^{-}\right)}{\left\|\mathbf{v}^{+}\right\|^{2}+k_{q}\left\|\mathbf{v}^{-}\right\|^{2}} .
\end{gathered}
$$

It can be seen that the variant terms of (26) and (27), i.e. oscillating active power and reactive power, are controlled by the coefficient $k_{q}$. These two parts of oscillating power are orthogonal and equal in maximum amplitude. Simulation results are obtained in Fig. 2 by sweeping parameter $k_{q}$. It is illustrated that either oscillating active power or 


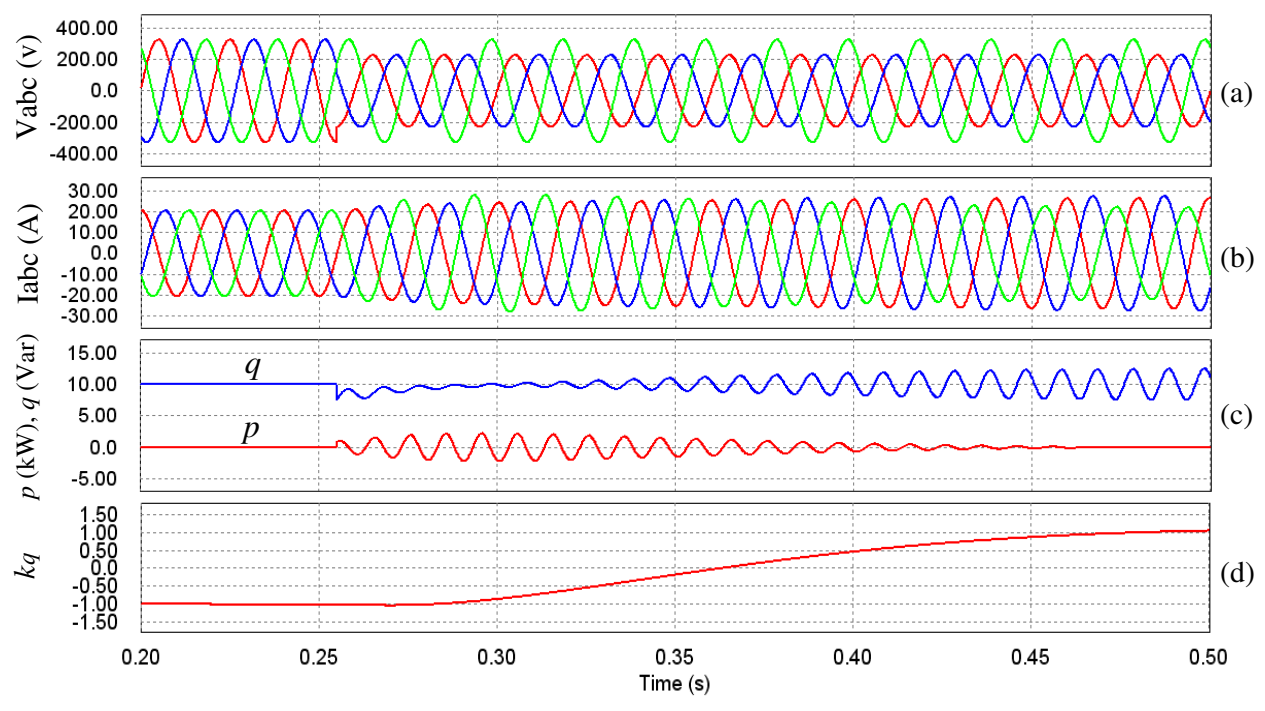

Fig. 2. Simulation results of the proposed reactive power control with $Q=10 \mathrm{kVar}, P=0$, where voltages of phase A and B dip to $70 \%$ at $\mathrm{t}=0.255 \mathrm{~s}$, (a) phase voltages, (b) injected currents, (c) instantaneous $\mathrm{p}$, q, and (d) adjustable coefficient $k_{q}$ sweeping from -1 to 1 .

oscillating reactive power can be controlled and even can be eliminated at the two extremes of the $k_{p}$ curve. This controllable characteristic allows to enhance system control flexibility and facilitates system optimization. It is pointed out that the strategies proposed in [9] namely positive-negativesequence compensation (PNSC), average active-reactive control (AARC), and balanced positive-sequence (BPS) are equivalent to the results of the proposed strategy when $k_{q}$ equals $-1,1$, and 0 , respectively.

\section{B. Active Power Control}

For given power $P$, the current reference for active power control can be derived similarly, as calculated by

$$
\mathbf{i}_{p}^{*}=\frac{P}{\left\|\mathbf{v}^{+}\right\|^{2}+k_{p}\left\|\mathbf{v}^{-}\right\|^{2}}\left(\mathbf{v}^{+}+k_{p} \mathbf{v}^{-}\right), \quad-1 \leq k_{p} \leq 1,
$$

where $k_{p}$ is the adjustable coefficient for active power control. Detailed derivation of (28) is presented in [13], as well as the applicability for optimization based on this strategy.

\section{StRategies For COMbined P\&Q CONTROL}

As already mentioned, some grid codes also require DG systems to contribute with reactive power [3]. For example, with respect to the amplitude drop of voltages, DG systems having agreements with grid operators are expected to deliver both active power and reactive power during grid faults. Hence the reference currents for this case, named $\mathbf{i}_{p q}^{*}$, can be derived by adding (25) and (28), as expressed by

$$
\begin{aligned}
\mathbf{i}_{p q}^{*}=\mathbf{i}_{p}^{*}+ & \mathbf{i}_{q}^{*}=\frac{P}{\left\|\mathbf{v}^{+}\right\|^{2}+k_{p}\left\|\mathbf{v}^{-}\right\|^{2}}\left(\mathbf{v}^{+}+k_{p} \mathbf{v}^{-}\right) \\
& +\frac{Q}{\left\|\mathbf{v}^{+}\right\|^{2}+k_{q}\left\|\mathbf{v}^{-}\right\|^{2}}\left(\mathbf{v}_{\perp}^{+}+k_{q} \mathbf{v}_{\perp}^{-}\right)
\end{aligned}
$$

with $-1 \leq k_{p} \leq 1,-1 \leq k_{q} \leq 1$.

It can be seen that there are infinite combinations for (29) with independent coefficients $k_{p}$ and $k_{q}$. This also implicates that the linear controllability benefiting from previous independent control strategies does not really exist. In order to preserve the controllability, two joint strategies are proposed to simplify (29) by linking the two coefficients.

\section{A. Joint Strategy with Same-Sign Coefficients}

By setting $k_{p}=k_{q}=k_{p q}$ in (29), reference current calculations are simplified and rewritten as

$$
\mathbf{i}_{p q}^{*}=\frac{S}{\left\|\mathbf{v}^{+}\right\|^{2}+k_{p q}\left\|\mathbf{v}^{-}\right\|^{2}} \mathbf{R}(\varphi)\left(\mathbf{v}^{+}+k_{p q} \mathbf{v}^{-}\right),
$$

where $S$ is the apparent power with $P=S \cos \varphi, Q=$ $S \sin \varphi$, and $\varphi$ the power factor angle. Since the $\alpha-\beta$ reference frame is used in the experiments, it can be derived that

$$
\mathbf{R}(\varphi)=\left[\begin{array}{cc}
\cos \varphi & \sin \varphi \\
-\sin \varphi & \cos \varphi
\end{array}\right]
$$

Note that $\mathbf{R}(\varphi)$ will be different in the a-b-c reference frame.

On the basis of (30), the resulting currents and oscillating powers can now be predicted and adaptively adjusted. To help understanding, a vector diagram representing voltage and current trajectories and the relationship between oscillating power are plotted with $k_{p q}$ as an adjustable parameter under an unbalanced voltage dip, where $\varphi=30^{\circ}$.

As shown in Fig. 3(a), when $k_{p q}$ changes from 1 to -1 , the length of current vectors changes and reaches a minimum value at $k_{p q}=0$. In Fig. 3(b), the amplitudes of the oscillating powers also vary with the change of $k_{p q}$, which can be predicted by substituting (30) into (7) and (8). Note that when $\varphi$ is not $0^{\circ}$ or $90^{\circ}$, i.e. active power and reactive power are 


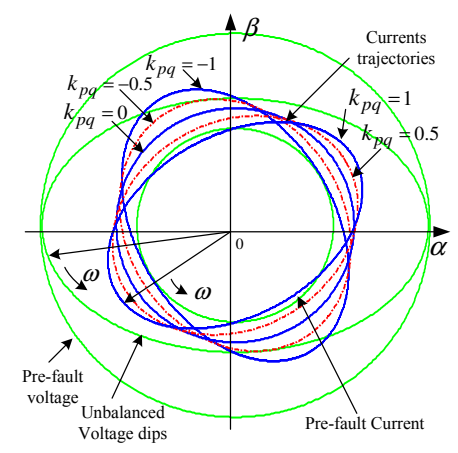

(a)

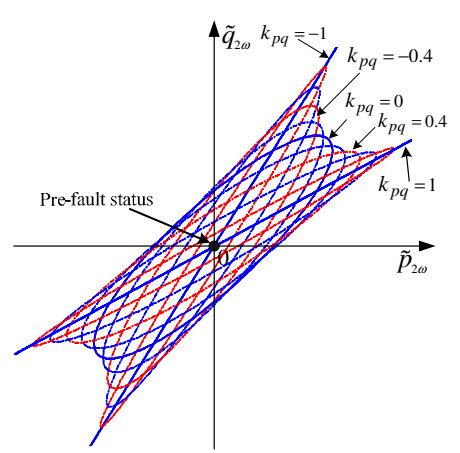

(b)

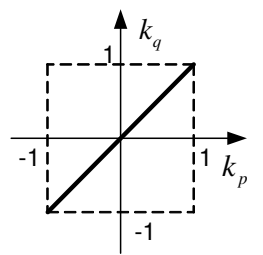

(c)

Fig. 3. Graphic representation of (a) grid voltage and current trajectories before and after unbalanced voltage dips in the stationary frame, and (b) relationship between oscillating active power $\tilde{p}_{2 \omega}$ and reactive power $\tilde{q}_{2 \omega}$ with $k_{p q}$ as an adjustable parameter under the joint strategy of (c), where $k_{p}=k_{q}=k_{p q}$.

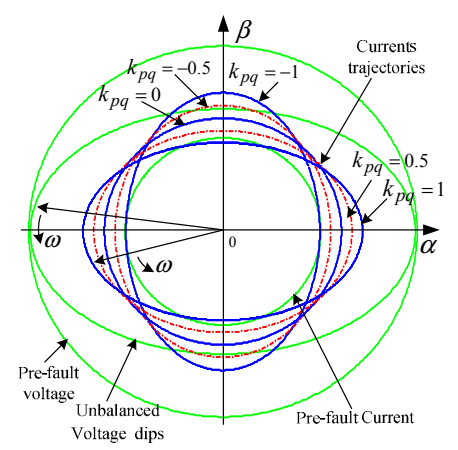

(a)

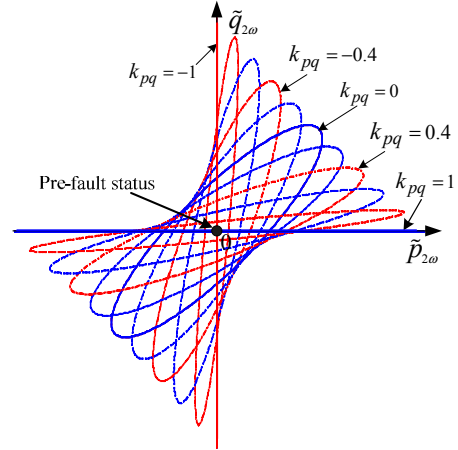

(b)

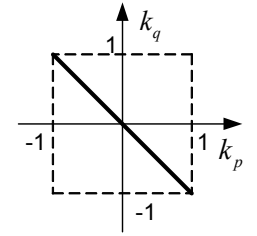

(c)

Fig. 4. Graphic representation of (a) grid voltage and current trajectories before and after unbalanced voltage dips in the stationary frame, and (b) relationship between oscillating active power $\tilde{p}_{2 \omega}$ and reactive power $\tilde{q}_{2 \omega}$ with $k_{p q}$ as an adjustable parameter under the joint strategy of (c), where $k_{p}=-k_{q}=k_{p q}$.

not zero, $\tilde{p}_{2 \omega}$ or $\tilde{q}_{2 \omega}$ cannot be eliminated since either active power or reactive power delivery will introduce oscillating power at the two extremes of $k_{p q}$.

\section{B. Joint Strategy with Opposing-Sign Coefficients}

By setting $k_{p}=-k_{q}=k_{p q}$ in (29), the reference current is represented by

$$
\begin{aligned}
\mathbf{i}_{p q}^{*} & =\frac{S \cos \varphi}{\left\|\mathbf{v}^{+}\right\|^{2}+k_{p q}\left\|\mathbf{v}^{-}\right\|^{2}}\left(\mathbf{v}^{+}+k_{p q} \mathbf{v}^{-}\right) \\
& +\frac{S \sin \varphi}{\left\|\mathbf{v}^{+}\right\|^{2}-k_{p q}\left\|\mathbf{v}^{-}\right\|^{2}}\left(\mathbf{v}_{\perp}^{+}-k_{p q} \mathbf{v}_{\perp}^{-}\right) .
\end{aligned}
$$

Illustrative plots are drawn in Fig. 4. It can be seen from (32) that this joint strategy actually requiring twice the computation time of joint strategy $A$. Fortunately, zero $\tilde{p}_{2 \omega}$ or $\tilde{q}_{2 \omega}$ can be achieved at the two extremes of $k_{p q}$, as shown in Fig. 4 (b). Similar to joint strategy $A$, when shifting $k_{p q}$ towards zero the length of current vectors decreases and the current trajectory tends to be a circle.

Therefore it can be summarized that the simple adaptive controllability of independent power control is preserved in the two joint strategies above. This enables DG systems to be optimized under unbalanced voltage dips, e.g. the output power maximization, and the limitation of oscillating active power / reactive power.

\section{EXPERIMENTAL RESULTS}

To verify the proposed strategy, experiments are carried out on a laboratory experimental system constructed from a four-leg inverter that is connected to the grid through LCL filters, as shown in Fig. 5. The system parameters are listed in Table I. By using a four-leg inverter, zero-sequence currents can be eliminated when the grid has zero-sequence voltages. For the cases where the zero-sequence voltage of unbalanced grid dips is isolated by transformers, a three-leg inverter can be applied. A $15 \mathrm{kVA}$ three-phase programmable AC power source (SPITZENBERGER+ SPIES DM 15000/PAS) is used to emulate the unbalanced utility grid, and the distributed source is implemented by a dc power supply. The controller is designed on a dSPACE DS1104 setup by using Matlab / Simulink.

\section{A. Control Realization}

The proposed controller is realized with a double-loop current controller, which consists of an outer control loop 


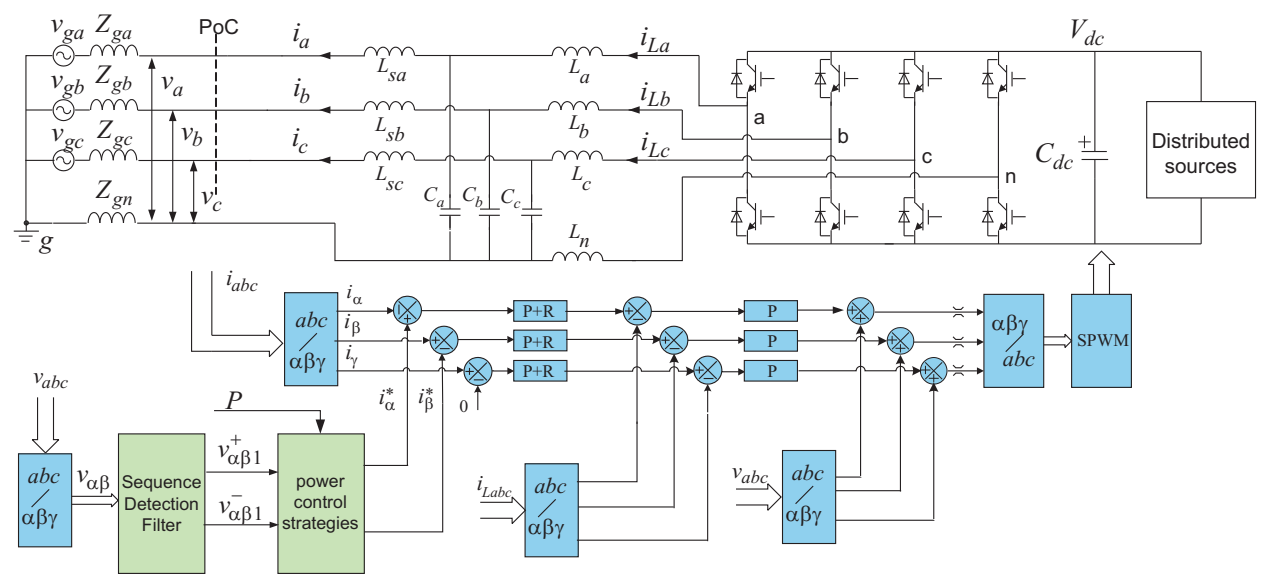

Fig. 5. Circuit diagram and control structure of experimental four-leg inverter system.

TABLE I

SYSTEM PARAMETERS

\begin{tabular}{|c|l|l|}
\hline Description & Symbol & Value \\
\hline Output filtering inductor & $L_{s a, b, c}$ & $2 \mathrm{mH}$ \\
\hline Output filtering capacitor & $C_{a, b, c}$ & $5 \mu \mathrm{F}$ \\
\hline Output filtering inductor & $L_{a, b, c}$ & $2 \mathrm{mH}$ \\
\hline Neutral filtering inductor & $L_{n}$ & $0.67 \mathrm{mH}$ \\
\hline DC-link voltage & $V_{d c}$ & $750 \mathrm{~V}$ \\
\hline DC-link capacitors & $C_{d c}$ & $4400 u F / 900 V_{d c}$ \\
\hline Switching frequency & $f_{s w}$ & $16 \mathrm{kHz}$ \\
\hline System rated power & $S_{r a t}$ & $15 \mathrm{kVA}$ \\
\hline Tested apparent power & $\mathrm{S}$ & $2500 \mathrm{VA}$ \\
\hline
\end{tabular}

with proportional-resonant (PR) controllers for eliminating the steady-state error of the delivered currents, and an inner inductor current control loop with simple proportional gain to improve stability. In addition, a feed-forward loop from the grid voltages is used to improve system response to voltage disturbances.

The control for both positive-sequence and negativesequence components would be much too complicated and computation-time consuming when conventional PI control with coordinate transformation is used. Furthermore, the sequence detection of feedback currents can be left out. Therefore, it is preferred to choose a PR controller in the stationary frame. A quasi-proportional-resonant controller with high gain at the fundamental frequency is used

$$
G_{i}(s)=K_{p}+\frac{2 K_{r} \omega_{b r} s}{s^{2}+2 \omega_{b r} s+\omega_{1}^{2}},
$$

where $K_{p}$ is the proportional gain, $K_{r}$ is the resonant gain, $\omega_{1}$ denotes the fundamental radian frequency, and $\omega_{b r}$ the equivalent bandwidth of the resonant controller. A detailed design for the PR controller has been presented in [14], it is not duplicated here. Through optimizing, the parameters used in the experiment are $K_{p}=2, K_{r}=100$, and $\omega_{b r}=10 \mathrm{rad} / \mathrm{s}$.

Since the whole controller is designed in the stationary frame, the sequence detection of grid voltages is also realized

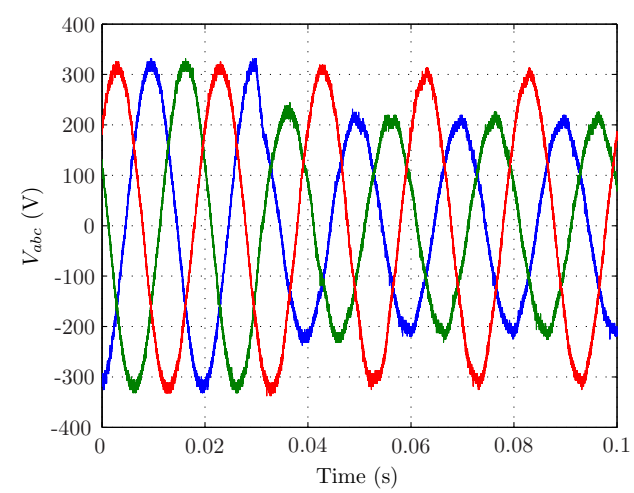

Fig. 6. Emulated grid voltages to be faulty at $\mathrm{t}=0.03 \mathrm{~s}$, where phases $\mathrm{A}$ and B dip to $70 \%$.

based on a stationary frame filter cell in the $\alpha-\beta$ frame [15]. The basic filter cell can be easily implemented using a multistate-variable structure. Besides, a high performance output can still be achieved under distorted grid voltages.

Concerning the power factor angle $\varphi$, two values are tested in the experiment. Firstly, a slightly modified approach is used here to calculate the angle $\varphi$ according to the grid code in [3]. Specifically, the DG system should inject at least $2 \%$ of the rated current for each percent of the fundamentalsequence voltage dip. Therefore the desired angle $\varphi$ is calculated by

$$
\varphi=\sin ^{-1}\left(2 \frac{\left|V^{+}-V_{N}\right|}{V_{N}}\right)
$$

where $V_{N}$ is nominal voltage amplitude, and $V^{+}$the positivesequence voltage amplitude. Furthermore, it is also required in [3] that a reactive power output of at least $100 \%$ of the rated current is possible when necessary. Hence also $\varphi=90^{\circ}$ is assigned directly to test a complete power change from active power to reactive power.

Note that dc-link voltage control is not added here. Usually, 

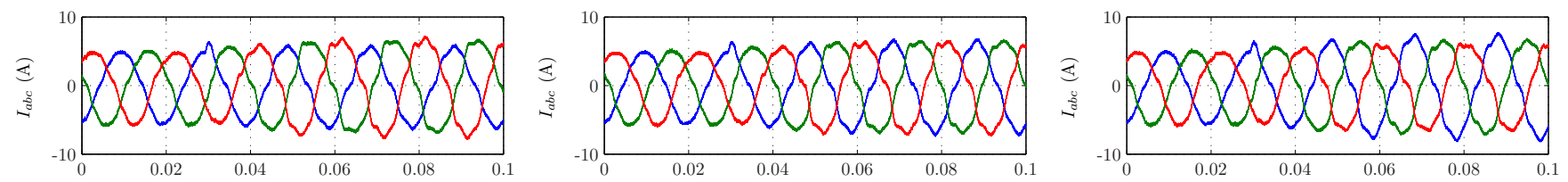

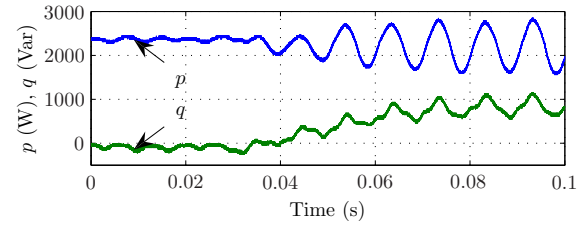

(a)

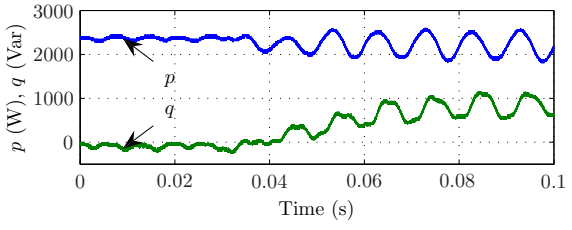

(b)

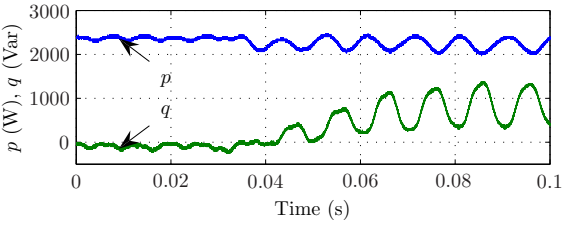

(c)

Fig. 7. Experimental results of the joint strategy A with $k_{p q}$ set to (a) 1, (b) 0 , and (c) -1 , where the waveforms from the top down are injected currents and instantaneous power when $\varphi=23^{0}$.
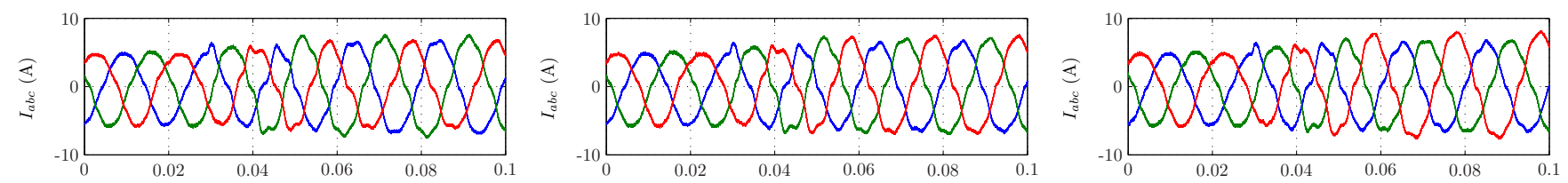

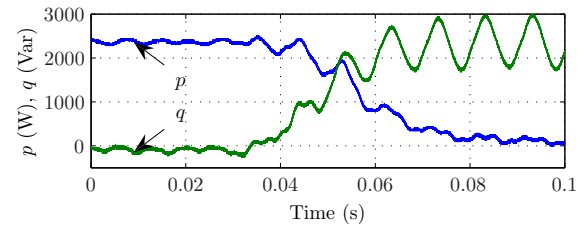

(a)

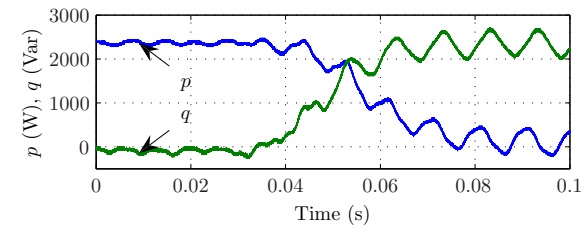

(b)

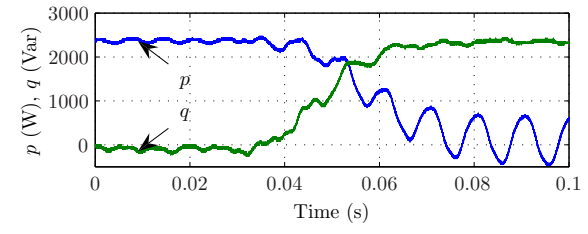

(c)

Fig. 8. Experimental results of the joint strategy A with $k_{p q}$ set to (a) 1 , (b) 0 , and (c) -1 , where the waveforms from the top down are injected currents and instantaneous power when $\varphi=90^{\circ}$.

a dc-link voltage control loop is included in the control structure, for instance, in a rectifier system [6] or for a wind turbine inverter [7]. The dc bus in the experimental system is only controlled by the dc power supply with a quite low bandwidth to maintain a stable dc bus in an average sense. Since the experiment intends to investigate the effects of the proposed strategy when choosing different $k_{p q}$, it is convenient to leave out the dc voltage control in order to only observe the performance of the proposed strategy.

\section{B. Experimental Results}

By shifting the controllable parameter $k_{p q}$, the system is tested under unbalanced voltage dips with the joint strategies. In order to capture the transient reaction of the system, three situations are intentionally tested for comparison at the start moment voltage dips.

As shown in Fig. 6, grid voltages are emulated to be faulty at $\mathrm{t}=0.03 \mathrm{~s}$ where phases $\mathrm{A}$ and $\mathrm{B}$ dip to $70 \%$. Consequently, the power factor angle $\varphi$ derived in the control is $23^{\circ}$ and the corresponding results of joint strategy $A$ are obtained in Fig. 7. It can be seen that the reactive power support starts within half a cycle after voltage dips. As analyzed in Section IV, the instantaneous active power and reactive power always have oscillating power ripples, and the injected grid currents get balanced only when $k_{p q}$ gets near to zero. In case of $\varphi$ equals $90^{\circ}$, the joint strategy $A$ turns out to be a reactive power control strategy as expressed by (25). Therefore, comparing with the simulation results in Fig. 2 at the point of $k_{q}=-1$, 0 and 1, it can be seen that the results in Fig. 8 show the same effects on the regulation of oscillating power ripple and reference current.

Under the same test conditions, experimental results are also measured for joint strategy $B$. As shown in Fig. 9, zero oscillating reactive power and active power are achieved at $k_{p q}=1$ and -1 , respectively. When $k_{p q}=0$, the results of joint strategy $B$ are same as the results of joint strategy $A$, since both joint strategies only depend on positive-sequence components in this case. The results with $\varphi=90^{\circ}$ are given in Fig. 10. Comparing with the results in Fig. 8 of joint strategies $A$, it is easily found that both joint strategies turn out to be the same but needing an opposing sign of $k_{p q}$.

\section{CONCLUSION}

This paper proposes generalized strategies for independent active and reactive power control of distributed generation inverters operating under unbalanced voltage dips. Using 

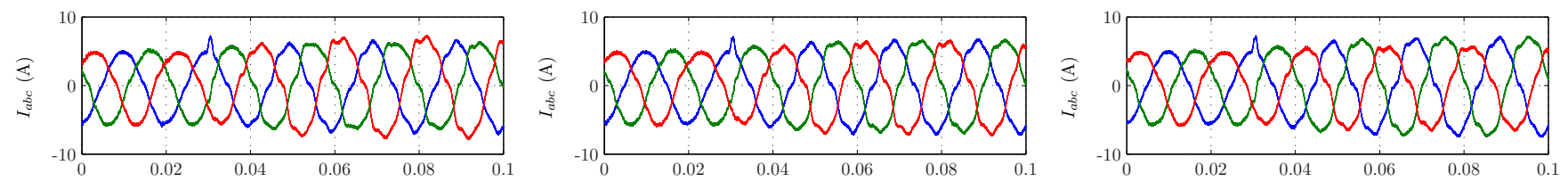

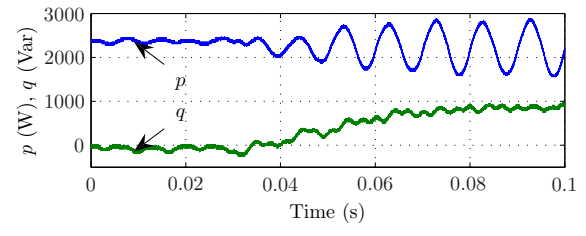

(a)

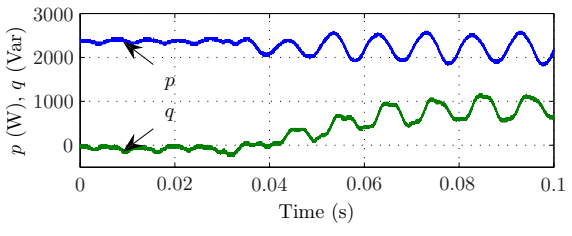

(b)

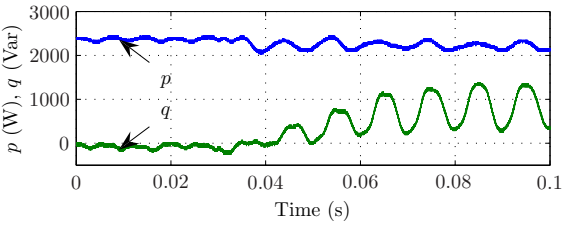

(c)

Fig. 9. Experimental results of the joint strategy B with $k_{p q}$ set to (a) 1 , (b) 0 , and (c) -1, where the waveforms from the top down are injected currents and instantaneous power when $\varphi=23^{\circ}$.
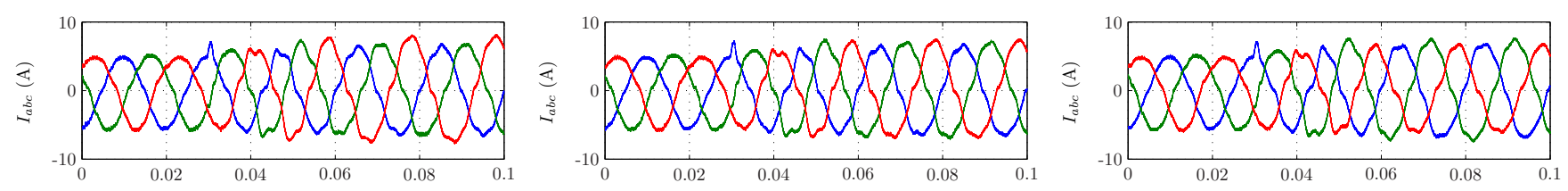

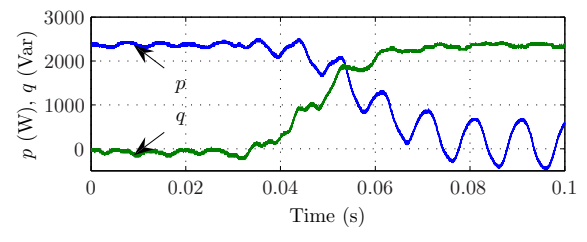

(a)

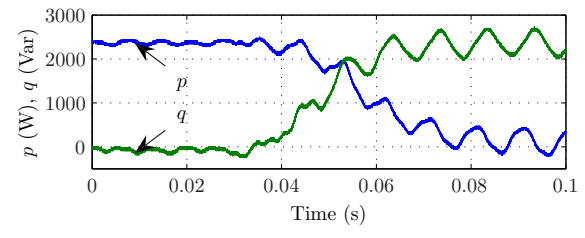

(b)

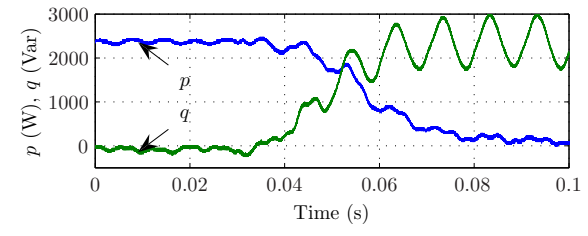

(c)

Fig. 10. Experimental results of the joint strategy B with $k_{p q}$ set to (a) 1, (b) 0 , and (c) -1, where the waveforms from the top down are injected currents and instantaneous power when $\varphi=90^{\circ}$.

derived formulas and graphic representations, the contributions of symmetric-sequence components to the instantaneous power and the interactions between symmetric sequences were explained in detail. Furthermore, for simultaneously controlling active and reactive power, two joint strategies are proposed that preserves the adaptive controllability. The flexible adaptivity of the proposed strategy allows it to cope with multiple constraints and to be optimized in practical applications. The performance of the proposed control strategies is verified by experiments.

\section{REFERENCES}

[1] M. F. McGranaghan, D. R. Mueller, M. J. Samotyj, "Voltage sags in industrial systems," IEEE Trans. Ind. Appl., vol. 29, no. 2, pp. 397-403, Mar./Apr. 1993.

[2] L. Zhang, and M. H. J. Bollen, "Characteristic of voltage dips (sags) in power systems," IEEE Trans. Power Del., vol. 15, no. 2, pp. 827-832, Apr. 2000.

[3] Grid Code for high and extra high voltage, E.ON Netz Gmbh, Apr. 2006.

[4] The Grid Code, National Grid Electricity Transmission Plc, U.K., May. 2009.

[5] Y. Suh and T. A. Lipo, "A control scheme in hybrid synchronousstationary frame for PWM AC/DC converter under generalized unbalanced operating conditions," IEEE Trans. Ind. Appl., vol. 42, no. 3, pp. 825-835, May/Jun. 2006.
[6] B. Yin, R. Oruganti, S. Panda, and A. Bhat, "An output-power-control strategy for a three-phase PWM rectifier under unbalanced supply conditions," IEEE Trans. Ind. Electron., vol. 55, no. 5, May 2008.

[7] H. Chong, R. Li , and J. Bumby, "Unbalanced-grid-fault ride-through control for a wind turbine inverter," IEEE Trans. Ind. Appl., vol.44, no. 3, pp. 845-856, May/Jun. 2008.

[8] P. Rodriguez, A. V. Timbus, R. Teodorescu, M. Liserre, and F. Blaabjerg, "Flexible active power control of distributed power generation systems during grid faults," IEEE Trans. Ind. Electron., vol. 54, no. 5, pp. 25832592, Oct. 2007.

[9] P. Rodriguez, A. V. Timbus, R. Teodorescu, M. Liserre, and F. Blaabjerg, "Independent PQ control for distributed power generation systems under grid faults," in Proc, IECON, 2006, pp. 5185-5190.

[10] H. Akagi, E. H. Watanabe, and M. Aredes, Instantaneous power theory and applications to power conditioning, IEEE press, 2007.

[11] F. Z. Peng, and J. -S. Lai, "Generalized instantaneous reactive power theory for three-phase power systems," IEEE Trans. Instrum. Meas., vol. 45, no.1, pp. 293-297, Feb. 1996.

[12] P. M. Andersson, Analysis of faulted power systems, New York: IEEE Press, 1995.

[13] F. Wang, J. Duarte, M. Hendrix, "Active power control strategies for inverter-based distributed power generation adapted to grid-fault ridethrough requirements," in Proc. EPE, 2009, to be published.

[14] D. Zmood and D. Holmes, "Stationary frame current regulation of PWM inverters with zero steady-state error," IEEE Trans. Power Electron., vol. 18, no. 3, pp. 814-822, May 2003.

[15] F. Wang, J. Duarte, M. Hendrix, "High performance stationary frame filters for symmetrical sequences or harmonics separation under a variety of grid conditions," in Proc. IEEE APEC, 2009, pp. 1570-157. 